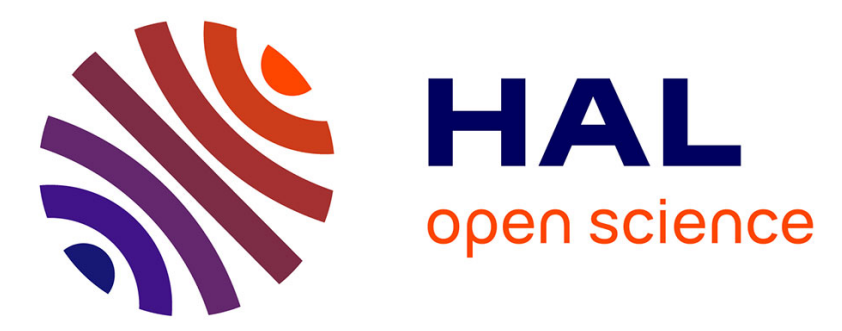

\title{
An Exploration of the Integration Challenges Inherent in the Adoption of ICT in an Education System
}

Isabel Meyer, Mario Marais, Merryl Ford, Sifiso Dlamini

\section{To cite this version:}

Isabel Meyer, Mario Marais, Merryl Ford, Sifiso Dlamini. An Exploration of the Integration Challenges Inherent in the Adoption of ICT in an Education System. 14th International Conference on Social Implications of Computers in Developing Countries (ICT4D), May 2017, Yogyakarta, Indonesia. pp.463-474, 10.1007/978-3-319-59111-7_38. hal-01650067

\section{HAL Id: hal-01650067 https://hal.inria.fr/hal-01650067}

Submitted on 28 Nov 2017

HAL is a multi-disciplinary open access archive for the deposit and dissemination of scientific research documents, whether they are published or not. The documents may come from teaching and research institutions in France or abroad, or from public or private research centers.
L'archive ouverte pluridisciplinaire HAL, est destinée au dépôt et à la diffusion de documents scientifiques de niveau recherche, publiés ou non, émanant des établissements d'enseignement et de recherche français ou étrangers, des laboratoires publics ou privés. 


\title{
An Exploration of the Integration Challenges Inherent in the Adoption of ICT in an Education System
}

\author{
Isabel Meyer $^{1}$, Mario Marais ${ }^{2, *}$, Merryl Ford ${ }^{2}$ and Sifiso Dlamini ${ }^{2}$ \\ ${ }^{1}$ Impact Advantage, Pretoria, South Africa \\ isabelmeyer amweb. co.za \\ ${ }^{2}$ CSIR Meraka Institute, Pretoria, South Africa \\ maraisecsir.co.za, mfordecsir.co.za \\ sdlaminidcsir.co.za
}

\begin{abstract}
The high failure rate of development interventions is well known. An approach to sustainable interventions is defined, based on a systems perspective that focuses on the ability of a system to integrate an intervention. The design of an intervention requires an understanding of the current state of the system from the perspective of being able to realise the intended benefit. This is called the readiness of the system, and is constituted by the level of maturity of the essential elements and the nature of the interrelationships that are required to realise and sustain the benefits. Interventions can be designed to match the current readiness of the system and to define the system changes toward the desired end state. These principles were developed during the implementation of an ICT for Rural Education (ICT4RED) project in the Eastern Cape province of South Africa. The practical implications for project design, execution and handover to the education system are illustrated.
\end{abstract}

Keywords: Sustainability, ICT in education, Systems thinking, System integration, ICT4D

\section{Introduction}

The high failure rate of development interventions bears testimony to the urgent need for new approaches. The use of technology in general and ICT in particular, has a poor track record, with quoted failure rates of as high as $80 \%$ [1]. The significant investment in ICT4D is characterised as being "limited" or "largely unsuccessful" [2]. While ICT4D is often seen as the "silver bullet" to development problems, its dual role of reducing the digital divide and fulfilling development objectives is seen as contributing to its failure [3]. In this context, we explore the sustainability of interventions, with specific focus on the integration of an ICT4D intervention into its intended environment.

Sustainability is an often-used, but also often ill-defined, concept. Heeks [4] emphasizes this when stating that "sustainable development is an empty slogan: continuously invoked but never examined." While seen as key to the future success of ICT4D 
[5], authors define the concept of sustainability from perspectives that range from classical views related to resource preservation [6] to the ability of a project or intervention to sustain itself without outside support $[7,8]$. The research programme in which this work is embedded was developed out of the participation of the researchers since 2008 in the implementation of ICT4D initiatives. Projects, funded by South African national government departments, used a mainly top-down and technologycentric approach in the development contexts of rural broadband access $[9,10]$, the deployment of telecentres in rural areas [11], and the deployment of ICTs in rural schools [12]. Based on these experiences, we adopt a pragmatic perspective on sustainability, and focus on sustaining the benefits that are created by an ICT4D project within its context. We therefore define sustainability as the ability to sustain the anticipated benefits of the project or programme, over an appropriate period of time, for pre-defined project participants. Sustainability is viewed from a systems perspective, by considering the elements that are essential to make things work in the long run, as well as the relationships between them. From this perspective, the sustainability of an intervention relates to how well the system (the participating organisation or community) is able to absorb a project into normal operations.

This focus of this paper is a conceptual approach to integrate ICT4D projects into their implementation environment, by considering pathways and strategies towards systemic change, the use of a modular implementation framework, and the application of an implementation readiness framework. The final framework was developed to assess readiness of an environment before the implementation of an ICT4D project, with the aim of designing the project in such a manner that the intervention meets the readiness of the community to adopt the intervention. Section 2 takes a conceptual perspective on the integration problem, the project in the context of a system, and pathways toward systemic change. Section 3 describes the ICT for Rural Education (ICT4RED) project in the Eastern Cape province of South Africa [12] and the implementation framework used. Section 4 applies the implementation readiness framework to the ICT4RED project and reflects on the benefits of taking a systemic view on the sustainability of ICT4D implementations.

\section{The problem of integration}

\subsection{Introduction}

Through appropriate design, an ICT4D project (similar to any ICT project), aims to deliver technology to achieve specific objectives. As such, a linear approach from technology design through implementation and ultimately transfer to users is often followed, and projects or programmes are designed accordingly.

However, ICT4D projects are in many respects fundamentally different from commercial ICT projects, and failure is to some extent the result of the unique nature of IC4D projects and their implementation environment [2, 17]. Based on project experience, the authors have identified the following as differentiating characteristics of ICT4D projects [14]. 
Table 1. The differentiating characteristics of ICT4D projects

\begin{tabular}{|c|c|}
\hline $\begin{array}{l}\text { Project phase: } \\
\text { Commercial ICT project }\end{array}$ & ICT4D project \\
\hline $\begin{array}{l}\text { Single proposal with budgets and } \\
\text { timelines }\end{array}$ & $\begin{array}{l}\text { Many proposals to many different funders; Unclear } \\
\text { objectives }\end{array}$ \\
\hline Conceptualisation & $\begin{array}{l}\text { Ambitious concept; Unknown or unfamiliar project } \\
\text { environment }\end{array}$ \\
\hline Design & Design by learning \\
\hline Solution development & Resource-rich solution for a resource-poor world \\
\hline Implementation & Unexpected challenges \\
\hline Training and maintenance & $\begin{array}{l}\text { Limited literacy; Remote locations; Low skills and } \\
\text { technology base }\end{array}$ \\
\hline
\end{tabular}

Some of these differences are attributable to the divergence between resource-rich and resource-poor environments (such as differences in literacy, skills, technology base, and the ability to maintain technology). Others are rooted in the unfamiliarity of the implementation environment to the implementation team, and the inability to predict uptake and adoption, given these inherent differences. Such uncertainties render the path to progress unclear.

Given these differences, the integration of an ICT4D solution into the community or organisational system where it is intended to reside presents unique challenges. For example, limited budgets would prevent an organisational environment from meeting the technology support requirements. Similarly, over-ambitious technology designs could be difficult to integrate into environments that are unfamiliar with sophisticated solutions, from a user as well as a support perspective.

\subsection{Methodology}

A literature study was conducted to determine the current state of research into the transition of an ICT4D project into a functional part of a sustainable system. Systems thinking was adopted as the conceptual framework for analysis of the current research, and was augmented by the researchers' own practical expertise. This approach was used as basis for the development of a systems-based approach for the integration of ICT4D projects within implementation environments.

\subsection{Approaches to the design and delivery of ICT4D projects}

Solutions to the unique ICT4D project challenges (see Table 1) have focused on various elements of the process of designing and delivering technology solutions. These include a focus on alternative approaches to solution design, such as addressing the 
design-reality gap $[3,15,16]$, participatory design methods (e.g., $[17,18]$ ), frugal technology design [19], or design for resource constraints [13]. Other remedies include alternative approaches to project transfer and scaling (e.g., [20, 21]). Project or process-wide approaches include project planning and design for sustainability [21], project roadmaps [1], and frameworks to guide development [22]. These solutions are all aimed at fixing a linear development process in such a manner that the inherent peculiarities of ICT4D projects are catered for.

Participatory design is seen by many authors as a means of developing solutions that will integrate well. Not many approaches focus on developing the capacity to integrate the ICT4D solution into the environment where it should reside. The project or programme remains an external process in which community members may participate, but that ultimately needs to be transferred into the "foreign" environment where it will reside. While the extent of social embeddedness of a project has been described [23], the method of achieving embeddedness, as well as the dimensions in terms of which embeddedness is required, could benefit from further exploration.

\subsection{A project or programme enhances a system}

In order to arrive at sustained systemic change, an approach is required in which a "project" or "programme" would alter the fundamental relationships between entities in the system. A flexible and responsive approach is required that would allow the intervention to be designed for, and progress in accordance with, the increasing readiness and maturity of the system. For example, an ICT4D solution that is aimed at enhancing teaching and learning should be delivered in line with the capacity of the education system as a whole to absorb and support the intervention (see Section 3).

To this end, we conceptualise the environment within which a project or programme will reside as a collection of entities and relationships. These could include organisational processes, structures, capabilities, culture, political influences, resources, social or community groups, etc. These elements and relationships would be modelled depending on the nature of the problem under consideration.

The project or programme would be seen as a means of affecting these entities and relationships in such a manner that change would be sustained. Here, the balance between entities needs to be considered, and interventions need to be mindful of the fact that relevant elements need to be affected in a balanced manner to achieve sustained change. For example, an over-focus on technology would be meaningless in an environment where basic computer literacy is lacking, and where the focus should rather be on the development of literacy (entity) and strengthening of the sharing of information (relationship) within communities of practice.

\subsection{Pathways to systemic change}

The concepts outlined above imply that the project or programme changes the state of the system from an initial to a changed reality that is capable of sustaining the benefits that are brought about by the project or programme. This changed reality is reflected in changed entities as well as in changed relationships between entities. The progres- 
sion can be represented as a shift from a current state (readiness) to the intended state, based on the intended change that should be brought about, to the long-term desired state, associated with long-term desired outcomes. This can be represented as follows:

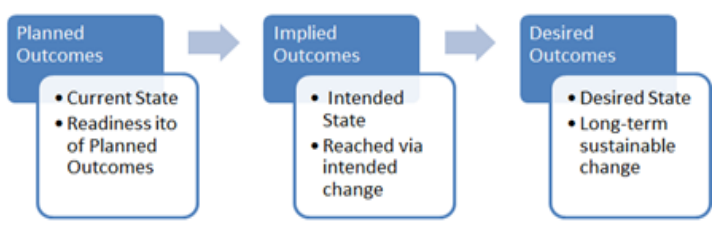

Fig. 1. A pathway to a system state that delivers desired outcomes (Source: researchers)

In the above representation, the initial state of readiness determines the initial approach that can be followed by the project. To this end, it is important to be clear about the intended benefits of the programme, the systemic elements and relationships that are required to sustain such benefits, and the pathway that needs to be followed to achieve the desired change. Instead of focusing on a linear progression from design through implementation and transfer, the focus is to develop an insider's perspective on the system, and to identify the key entities and relationships between them. These should be analysed to understand the readiness to absorb the benefits of the project or programme, after which existing or additional entities and relationships should be developed so as to mature the systemic ability to absorb change.

In this process, appropriate pathways to change should be identified. Given our formulation, the premise is that sustainability is inherent in the ability of the system to absorb change. This systemic approach to the development of an appropriate artefact incorporates Ali and Bailur's concepts of unintended consequences, improvisation, and bricolage, the latter of which means "tinkering through the combination of resources at hand" [24:5].

The manner in which the pathway is constructed becomes critical to the extent of success that can be attained. Here, modularity becomes a key enabler of gradual change that is matched to the readiness of the system. By designing an artefact to have different modules, the flexibility that is called for in the design of ICT4D artefacts [25] is catered for. Modules can be delivered in accordance with the readiness of the system to engage with different levels of complexity, and modules can be used to strengthen different entities and relationships towards increased readiness to absorb more complex solutions. In addition, to allow for flexibility in the intervention, such an approach also allows for accommodation of resource constraints. In the education example outlined below, different modules (technology, professional development, community engagement, etc.) could be delivered depending on the readiness of the system to absorb and afford different parts of the intervention. 


\section{Integrating ICT4D in education}

The ICT for Rural Education (ICT4RED) project, undertaken by CSIR Meraka and sponsored by multiple government departments, was particularly successful in implementing technology in 26 deep rural pilot schools, and in empowering teachers to comfortably use tablets in their day-to-day teaching activities [25]. It was not as successful in institutionalising change within the Eastern Cape Department of Education (ECDoE) [25].

The project undertook a purposeful systems approach in its design, initially identifying 6 implementation modules that needed to be focused on [12] in order to ensure sustainability and integration of the schools into the education ecosystem.

This implementation model was tested, extended, and improved throughout the project, resulting in an eventual 12 modules [12], categorised under "Governance and Processes", "Technology" and "People and Practices" as indicated in Figure 2.

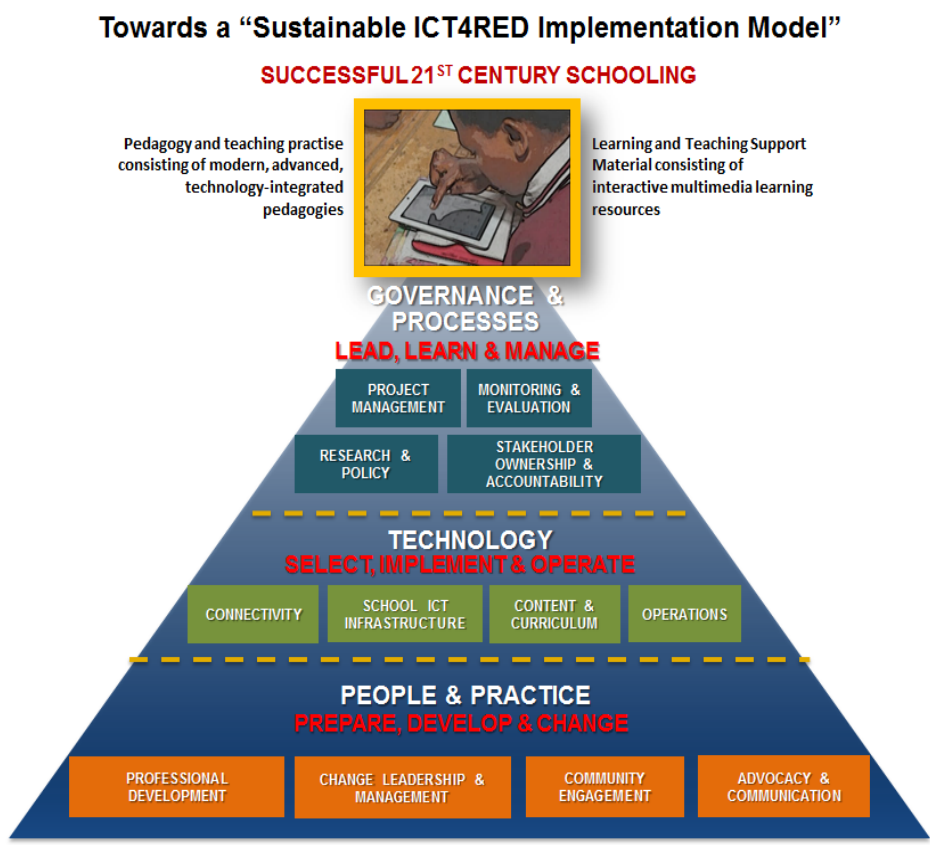

Fig. 2. ICT4RED 12 Component Implementation Model - a systems approach towards sustainability of ICT in schools [12]

Unfortunately, despite the existence of a protocol document between the partner government departments, the project team underestimated the level of "unreadiness" of the district and provincial education entities [26], and did not afford them sufficient focus. This resulted in handover to the ECDoE being problematic. There was difficulty in obtaining commitment with regard to both budget and resources, as well as a general low prioritisation of the needs of the project. The problem was not an unwill- 
ingness to incorporate the project into the provincial educational environment, but reflected a lack of resources and a structural design problem regarding integration of ICT initiatives into the existing system. Without the support of the district and province, it becomes difficult for the schools to continue to sustain the change.

In reflecting how the learning from this project could be generalised for all ICT4D projects, the 12 modules were turned into a matrix. Each module can be shaded according to the intensity of effort needed to adequately make provision for weaknesses of various entities and their relationships. Thus the modules can be adjusted to fit the needs within a target environment. The aim is to have a balanced system in which modules do not overpower each other. In a balanced system, the intervention needs to adjust to the level of readiness of each focus area. For example, in the context of ICT4RED - where there was a general lack of skills ("People \& Practice") and where there were challenges within the stakeholder environment ("Governance \& Processes") required extra effort—investment and focus was needed in the darkly shaded modules as demonstrated in Figure 3.

\begin{tabular}{|c|c|c|}
\hline $\begin{array}{c}\text { GOVERNANCE \& } \\
\text { PROCESSES } \\
\text { LEAD, LEARN \& MANAGE }\end{array}$ & $\begin{array}{c}\text { TECHNOLOGY } \\
\text { SELECT, IMPLEMENT, \& } \\
\text { OPERATE }\end{array}$ & $\begin{array}{c}\text { PEOPLE \& PRACTICE } \\
\text { PREPARE, DEVELOP \& } \\
\text { CHANGE }\end{array}$ \\
\hline $\begin{array}{c}\text { PROJECT } \\
\text { MANAGEMENT }\end{array}$ & CONNECTIVITY & $\begin{array}{c}\text { PROFESSIONAL } \\
\text { DEVELOPMENT }\end{array}$ \\
\hline $\begin{array}{c}\text { MONITORING \& } \\
\text { EVALUATION }\end{array}$ & $\begin{array}{c}\text { SCHOOL ICT } \\
\text { INFRASTRUCTURE }\end{array}$ & $\begin{array}{c}\text { CHANGE LEADERSHIP \& } \\
\text { MANAGEMENT }\end{array}$ \\
\hline $\begin{array}{c}\text { RESEARCH \& POLICY } \\
\text { CONTENT \& CURRICULUM }\end{array}$ & $\begin{array}{c}\text { COMMUNITY } \\
\text { ENGAGEMENT }\end{array}$ \\
\hline $\begin{array}{c}\text { STAKEHOLDER } \\
\text { OWNERSHIP \& } \\
\text { ACCOUNTABILITY }\end{array}$ & OPERATIONS & $\begin{array}{c}\text { ADVOCACY \& } \\
\text { COMMUNICATION }\end{array}$ \\
\hline \multicolumn{2}{|c|}{ Shade of block indicates leVel of EFFORT, INVESTMENT \& FOCUS }
\end{tabular}

Fig. 3. ICT4RED 12 Component Implementation Model - customised focus according to the strengths and weaknesses in the target environment [26]

In order to adjust an intervention to make provision for the strengths and weaknesses within the target environment so that the change can be absorbed into the system, it is critical to evaluate the readiness of the system. 


\section{The development and implementation of the readiness framework}

\subsection{Methodology}

On completion of ICT4RED, there was a need to understand the issues that had not worked well in the project. In order to develop a deep understanding of the dynamics at school and district levels, immersion into this system was required. An ethnographic approach was adopted and a researcher spent two periods of three and four weeks, respectively, at the schools and villages to conduct classroom observation and individual teacher interviews. In order to validate and supplement the researchers' experiences of the provincial system, the whole research team conducted two days of intensive individual interviews with senior provincial management and also held a focus group with teachers and district officials. Based on these inputs, the readiness framework was developed [28].

\subsection{The application of the implementation readiness framework}

\subsubsection{Introduction}

This section aims to provide a very brief overview of the implementation readiness framework. It illustrates how this framework helps with the analysis and understanding of the education system's readiness for ICT interventions in the ICT4RED context. It does so by listing the framework elements that were identified during the research (see below), an then describing how imbalances between elements affect the ability to sustain benefit. An application of the framework would highlight such imbalances, to be rectified through an appropriate intervention design.

The system comprises the provincial department of education with its structures (provincial, districts, circuits and schools), as well as all stakeholders (e.g. parents and funders) with direct or indirect involvement and interests in education [28]. The subsystems discussed here are the schools, the district, and the provincial head office departments.

The development of a readiness framework requires that the elements of the system and their preparedness for ICT interventions are studied [28]. The analysis of the data resulted in an implementation readiness framework with these elements:

- the quality of the management of the school

- $\quad$ prior exposure to ICT interventions

- school support structures (funders, sponsors and grants)

- the role of the community and politics

- the geographical location of the school

The elements listed above may also be ranked in terms of their relative degree of influence on the readiness of the school. For example, school support structures may be less influential than the quality of the school management [28]. The framework was designed to guide the process of examining different elements of the education system for their readiness to ensure sustained benefit of ICT interventions. The 
framework can be used to understand the status of different modules of the system, and identify the modules to focus on.

\subsubsection{Balance and Imbalance between the elements of a system}

Balance refers to the configuration of the key elements that are required for everything to work coherently at a systems level. The necessary elements should be present and resourced to a sufficient level. As discussed above, this applies to the school and also to the specific ICT4D implementation (as discussed in the ICT4RED 12 Component implementation model). The generic view of the readiness framework considers how ready the school should manage the operations associated with an ICT system and to develop capacity for the use thereof [28]. The hypothesis is that a school that has a good management team to execute management processes is likely to manage the initiative at the school level to ensure sustained benefit. However, this does not mean that good management is the only factor that will ensure successful implementation and incorporation of the initiative into schools. There are balances and imbalances that need to be understood when deciding what implementation is relevant for a particular school. For example, if the results from the readiness assessment indicate that a school meets all the requirements for a large scale ICT intervention, then implementers can implement at the appropriate scale. The framework helps implementers to scale interventions to be manageable by the school and not to overwhelm them.

A school is a system in itself, but is also enclosed in the larger system of circuits of schools that form part of a district. These in turn constitute the province, which is managed by the provincial head office.

In the case of the ECDoE, as mentioned earlier in this section, a lack of resources and a silo-based organisational structure creates imbalances in the system. For example, the system would provide for only one IT technician per district (e.g. 350 schools in Cofimvaba). If each school has to accommodate 30 tablets in addition to a few PCs, it is obvious that the introduction of the ICT4D intervention makes an already impossible task even worse. A subject advisor may be allocated to more than a hundred schools. Advisors are not necessarily computer literate, which means that they can are not able to use IT as a means to teach their subject and are unable to provide support and leadership to the schools to the required levels of competence.

Most interventions in schools in rural areas fail to be sustainable due to these systemic imbalances. Provincial departments have to institutionalise the initiatives that are implemented at school level to ensure that the benefits are sustained. On conclusiosion of the initiative, it has to be handed over to the provincial department or be sustained by the schools themselves. In general, departments may not have the relevant human or financial resources to provide support to the schools that are participatiing in a particular intervention.

The lack of resources at the province and district levels, and the inability of the national department to support the initiatives, leave the national system unprepared for ICT initiatives in the most impoverished schools, especially in rural areas. Even if the schools are equipped with the best technology and change management processes, and even if teacher professional development processes are executed, the unprepared- 
ness of the system to incorporate these interventions makes it difficult to sustain the benefits from ICT4D interventions. These therefore need to be designed to address the balance required within the sub-systems of the provincial system.

The framework also considers the readiness and balance of the implementation team and the funders. A team may, for example, need to facilitate the management of change. Since many of the rural schools in South Africa have never received large scale ICT interventions, the soft, technical, and managerial skills required to incorporate the project into the school are not readily available [28]. This calls for the implementation team to facilitate a change management process to equip the teachers and school management to sustain the intervention at the school, as was done in the ICT4RED project.

Funders need to be ready to learn about the system and improve their strategy. Funders often focus on the improvement of marks through large-scale ICT interventions, but neglect the status of the system and the diversity of influences on learner achievement. It was evident from the ICT4RED project that there is often no direct relationship between an ICT intervention at schools and the improvement of learner's marks [29] in the short term. The readiness of the funders can be referred to as their ability to change their mindsets about the purpose of funding and the strategies to achieve desired outcomes.

\section{Conclusions and recommendations}

The concept of sustainability has been defined in systems terms by describing the elements and the interrelationships that are required to sustain the benefits of an intervention. Analysis of the ICT4RED intervention showed that the modularity of a project is key to enabling gradual change from the current state of the system (the readiness), as defined from the perspective of being able to realise the desired benefits. A pathway from the current state to the end state of the system, based on the gradual increase of readiness via systemic change can be developed. An implementation readiness framework with five key elements was developed. The framework can be used to characterise the differences in readiness of schools, which can in turn be used to customise the implementation according to the initial configuration of weak and strong elements, and to scale the implementation appropriately.

The same concepts were applied to illustrate the readiness of the systems that support schools, namely the circuits of schools within a district that are managed within a provincial system by the provincial head office. Intervention design therefore has to take into account the nexus of the intervention (e.g. a school) and the supporting systems that would need to be ready to integrate the intervention into the system as a whole.

The work contributes to the ICT4D discourse in that it highlights the need for interventions to be designed in a manner that is cognisant of readiness (or not) of a community to adopt the intervention. It provides a tool that can be applied in practice to assess readiness, and to inform the appropriate pathway that needs to be followed to achieve incremental adoption of the intervention. 


\section{References}

1. Kettani, D., Moulin, B.: E-government for good governance in developing countries: Empirical evidence from the eFez project. London: Anthem Press (2015)

2. Dodson, L., Sterling, S., Bennet, J.: Considering Failure: Eight Years of ITID Research. Int. J. for Service Learning in Eng. 9, 2, 19-34 (2013)

3. Musiyandaka, D., Ranga, G., Kiwa, J.: An Analysis of Factors Influencing Success of ICT4D Projects: A Case Study of the Schools Computerisation. J. of Community Informatics 9, 4 (2013)

4. Heeks, R.: ICT4D 2016: New Priorities for ICT4D Policy, Practice and WSIS in a Post-2015 World. Development Informatics Working Paper Series: Paper 59. Manchester: Centre for Development Informatics, Institute for Development Policy and Management, SEED, University of Manchester (2014)

5. Heeks, R.: ICT4D2.0: The next phase of applying ICT for International Development. Computer 41, 6, 26-31 (2008)

6. World Commission on Environment and Development (WCED): Our Common Future. Oxford, UK: Oxford University Press (1987)

7. Harris, R.W., Kumar, A., Balaji, V.: Sustainable telecentres? Two cases from India, in: The Digital Challenge: Information Technology in the Development Context, S. Krishna and S. Madon (eds), Ashgate Publishing, Aldershot, pp. 124-135 (2003)

8. Bailey, A., Ngwenyama, O.: Toward entrepreneurial behavior in underserved communities: An ethnographic decision tree model of telecenter usage. Inf. Tech. for Development (2013). doi: 10.1080/02681102.2012.751571

9. Roux. K., Marais, M.: Design for Sustainability: Rural Connectivity with Village Operators, in: IEEE Global Humanitarian Technology Conference (GHTC): Technology for the Benefit of Humanity, 30 Oct. - Nov. 1, 2011, Seattle, Washington, pp. 522 - 527 (2011). doi:10.1109/GHTC.2011.58

10. Marais M.A.: Social capital in the Village Operator model for rural broadband internet access and use. Unpubl. Dr. Diss. Univ. Pretoria, Pretoria, South Africa (2016)

11. Smith, R., Cambridge, G., Gush, K.: Digital doorway computer literacy through unassisted learning in South Africa. CSIR Research and Innovation Conference: 1st CSIR Biennial Conference, CSIR International Convention Centre, 26-27 February 2006, Pretoria (2006).

Available at http://hdl.handle.net/10204/2676.

12. Ford, M., Botha, A., Herselman, M.: ICT4RED 12-Component Implementation Framework: A conceptual framework for integrating mobile technology into resource-constrained rural schools. IST Africa, 2014, Mauritius (2014)

13. Chen, J.: Computing within limits in ICT4D. First Monday 20, 8 (2015)

14. Meyer, I. A., Marais, M.A.: Design for Sustainability: Countering the Drivers of Unsustainability in Development Projects. J. of Community Informatics 11, 3 (2015).

Available at http://ci-journal.net/index.php/ciej/article/view/1169/1161. 
15. Heeks, R.: Information Systems and developing countries: Failure, success, and local improvisations. The Inf. Society 18, 101-112 (2002)

16. Barjis, J., Kolfschoten, G., Maritz, J.: A sustainable and affordable support system for rural healthcare delivery. Decision Support Systems 56, 223-233 (2013)

17. Steyn, J., Rampa, M., Marais, M.: Participatory development of ICT entrepreneurship in an informal settlement in South Africa. J. of Community Informatics 9, 4 (2013)

18. Shiang, C., Halin, A., Lu, M., CheeWhye, G.: Long Lamai Community ICT4D E-Commerce System Modelling: An Agent Oriented Role-Based Approach. The Elec. J. of Inf. Systems in Developing Countries 75, 5, 1-22 (2016)

19. Watson, R., Kunene, K., Islam, M.: Frugal Information Systems (IS). Inf. Tech. for Development 19, 2, 176-187 (2013). doi: 10.1080/02681102.2012.714349.

20. Foster, C., Heeks, R.: Innovation and scaling of ICT for the bottom-of-thepyramid. J. of Inf. Tech. 28, 296-315 (2013)

21. Pade, C.I.: An investigation of ICT project management techniques for sustainable ICT projects in rural developments. Master's dissertation, Rhodes University, Grahamstown, South Africa (2006)

22. Mamba, M.S.N., Isabirye, N.: A framework to guide development through ICTs in rural areas in South Africa. University of Fort Hare, East London, South Africa (2014)

23. Breytenbach, J., De Villiers, C. Jordaan, M.: Communities in control of their own integrated technology development. Inf. Tech. for Development 19, 2, 133-150 (2013)

24. Ali, M., Bailur, S.: The Challenge of "Sustainability" in ICT4D - Is Bricolage the Answer? In: Proceedings of the 9th International Conference on Social Implications of Computers in Developing Countries, Sao Paulo, Brazil (2007)

25. Herselman, M., Botha, A., Ford, M.: Designing and implementing an ICT4RED initiative. Designing and Implementing an Information Communication Technology for Rural Education Development (ICT4RED) Initiative in a Resource Constrained Environment: Cofimvaba School District, Eastern Cape, South Africa. Creative Commons, South Africa (2014)

26. Ford, M.: Discussion Document - ICT4RED Institutionalisation. Unpublished project report. CSIR Meraka Institute, Pretoria, South Africa (2016)

27. Blake, E., Tucker, W., Glaser, M.: Towards communication and information access for Deaf people. South African Comp. J. 54, 10-19 (2013)

28. Meyer, I., Marais, M., Dlamini, S.: Framework for assessing implementation readiness in ICT4E projects. Unpublished framework document. CSIR Meraka Institute, Pretoria, South Africa (2016)

29. Human Science Research Council (HSRC). Report on Monitoring Evaluation and Learning of the TECH4RED initiative. Pretoria, South Africa (2016) 